\title{
LEY ESCRITA E INTERPRETACIÓN, SEGÚN GÉNY
} WRITTEN LAW AND INTERPRETATION, ACCORDING TO GÉNY

\section{Gastón Alexander Velásquez Villamar*}

Resumen: El objetivo de este artículo es comprender la relación entre la ley escrita y la interpretación en los términos propuestos por François Gény, atendiendo a la descripción del fenómeno interpretativo y los elementos de su racionalidad. Este trabajo está estrictamente referido a su obra Método de interpretación y fuentes en Derecho Privado positivo, del cual establecemos las nociones de ley, interpretación y racionalidad que desarrolló el autor, así como sus principales ideas sobre la interpretación extensiva, la analogía, las reglas lógicas y los casos en que los elementos extrínsecos a la ley escrita se pueden considerar en la práctica de la interpretación. Terminaremos este artículo considerando algunas referencias del autor al método de la libre investigación científica, como sus reflexiones sobre los límites de la interpretación disociada de la voluntad del legislador. Teniendo en cuenta que esta es una investigación teórica, cuya fuente son textos impresos, la metodología empleada ha requerido del uso de los métodos histórico-lógico y analítico sintético. Como método de análisis de contenido se ha recurrido al análisis textual de los documentos considerados en la investigación.

Palabras clave: Analogía, fuentes del Derecho, interpretación, lagunas del Derecho, ley escrita

Abstract: The objective of this article is to understand the relationship between written law and the interpretation of the terms proposed by

\footnotetext{
* Magíster en Derecho Económico por la Universidad Andina Simón Bolívar (Quito, Ecuador). Profesor Invitado de Procedimientos y Recursos Administrativos en la Universidad Andina Simón Bolívar (Quito, Ecuador). https://orcid.org/0000-0003-07231904. gaston.velasquez@uasb.edu.ec
} 
François Gény, taking into account his description of the interpretive phenomenon and the elements of its rationality. This paper is strictly referred to his work titled "Method of Interpretation and Sources in Positive Private Law", from which we establish the notions of law, interpretation, and rationality that the author developed, as well as his main ideas on extensive interpretation, analogy, the logical rules and the cases in which the elements extrinsic to the written law that can be considered in the practice of interpretation. We will finish by considering some references by the author to the method of free scientific research, such as his reflections on the limits of the interpretation dissociated from the will of the legislator. This article responds to a theoretical investigation, whose source is printed texts, therefore the methodology used required analytical synthetic and historical-logical methods. As a content analysis method, the textual analysis of the documents considered in the research has been used.

Keywords: Analogy, Sources of Law, Interpretation, Lacuna and Loopholes of Law, Written Law

Sumario. I. Introducción. II. Línea de exposición del autor. II.1. La ley. II.2. La interpretación. II.3. La fórmula legislativa. II.4. La voluntad del legislador. II.5. Sobre la interpretación extensiva y restrictiva. III. Las nociones de ley y de interpretación. IV. Reglas básicas de interpretación. V. Los criterios brocárdicos. V.1. Cessante ratione legis, cessat lex ipsa. V.2. Inclusione unius fix exclusio alterius. V.3. Argumentum e contrario. V.4. Argumento "a pari" o "a simili". V.5. A majori ad minus. V.6. A minori ad majus. V.7. Ubi eadem ratio, idem jus. VI. El método de la libre investigación científica. VII. Conclusiones. Referencias.

\section{INTRODUCCIÓN}

Leo un libro o un artículo de Derecho, en especial si trata del rol político de la judicatura, de la ley como una fuente en retroceso frente a otras y con ella la quiebra de la autoridad del legislativo o la captura por alguna ideología política del sistema de fuentes del Derecho, y su nombre casi siempre aparece encabezando las citas y referencias. Me refiero a François Gény (1861-1959). Su obligada alusión no debería sorprender: este iusfilósofo influyó en el desarrollo metodológico y epistemológico del Derecho.

No obstante, las citas suelen referirse a su ensayo crítico de 1899, Método de interpretación y fuentes en derecho privado positivo. ¡Vaya coincidencia! En realidad, la extrañeza se desvanece al comprender que fue uno de sus primeros trabajos en el que reaccionó contra lo que entendía como 
el método jurídico de su tiempo, un reduccionismo del Derecho a una actividad jurídico-deductiva en el marco de la ley. Por lo tanto, no faltan quienes, para atacar a la ley, el sistema de fuentes o abogar por el activismo judicial, aunque no se preocupen en entender a Gény, se hagan de sus críticas en esta obra para enmascarar sus fines políticos.

Las ideas que se atribuyen al autor y a fuerza de repetirlas se han vuelto en tópicos son: (i) Gény es un antiformalista que ataca la jerarquía y función de la ley en el sistema de fuentes del Derecho, (ii) el postulado de plenitud del Derecho está equivocado, (iii) el Derecho presenta lagunas, (iv) se puede interpretar el Derecho por fuera de la ley, y (v) los jueces tienen libertad para adjudicar o administrar justicia indagando por fuera de la ley las posibles soluciones a los casos presentados.

En este contexto, este es el propósito del presente artículo, comprender la relación entre la ley escrita y la interpretación en los términos propuestos por Gény en su obra Método de interpretación y fuentes en Derecho Privado positivo (1925), quien señaló "en este estudio no atiendo más que a la interpretación de la ley, como doctrina o como motivo de una resolución judicial" (pp. 244-245). En consecuencia, no nos referiremos a otros tipos de interpretación, como por ejemplo la legislativa. Tampoco el artículo busca sintetizar su pensamiento o su método. De hecho, la mayoría de citas se refieren a la tercera parte del primer capítulo, titulada La ley escrita y su interpretación — salvo citas de otras secciones de su obra hechas por el mismo autor.

Para enfrentar la tarea revisaremos la línea de exposición del autor según su obra (Capítulo II). Repasaremos las nociones de la ley y de la interpretación, la relación dentro del fenómeno de las lagunas del Derecho y la necesidad de recurrir a otras fuentes como la equidad, con la finalidad de describir la práctica interpretativa del texto legislativo, sus causas y sus elementos de racionalidad (Capítulo III). Luego verificaremos los brocardos latinos cuyas relaciones lógicas informan del razonamiento que pueden merecer los enunciados normativos, así como los elementos característicos de la interpretación extensiva y la analogía (Capítulo IV). Finalmente, consideraremos las referencias del autor a su método de la libre investigación científica y sus reflexiones sobre los límites en las tendencias interpretativas del Derecho que observó a finales del siglo XIX (Capítulo V).

En el apartado metodológico de este trabajo se descompone el objeto de estudio según las nociones identificadas por el propio autor. En su desarrollo se recurre al método histórico-lógico y analítico sintético, cada uno en lo que corresponda en la descripción del fenómeno de la interpretación, sus relaciones lógicas, el método de la libre investigación 
científica y los límites de su praxis. De los resultados obtenidos se ha procedido al análisis textual, conforme el propósito de esta investigación.

\section{LÍNEA DE EXPOSICIÓN DEL AUTOR}

Nos referiremos a la línea de exposición de la tercera parte del capítulo primero de su obra, señalando los temas principales y el número del apartado correspondiente.

\section{II.1. La ley}

Desde el apartado 92 se reconoce la importancia de la ley en orden a su legitimidad, la cual radica en el modo democrático de producción. En los apartados 93 y 94 el autor busca explicar las distintas formas de racionalidad de la ley, así como identificar la autonomía legislativa y el campo de acción imperativa de la ley.

\section{II.2. La interpretación}

En el apartado 95 el autor desarrolla su opinión sobre la misión y los medios con los que cuenta el intérprete. El apartado 96 estudia los excesos en la interpretación de la ley. Mientras, en el apartado 97, encontramos una crítica a la escuela histórica respecto a que la fuente última del Derecho positivo es la conciencia popular y el rechazo de que se entienda a la ley de modo separado o diferente a la intención del legislador, advirtiendo que no se debería usar el texto de la ley para justificar algo contrario a lo que quiso instituir el legislador.

\section{II.3. La fórmula legislativa}

En el apartado 98 explica la interpretación como un volver a la fórmula legislativa (la voluntad del legislador), distinta a la fórmula gramatical que la expresa. Sin dejar de reconocer otros elementos de interpretación jurídica, la fórmula gramatical establece el marco de lo que la legislatura ha querido o sabido expresar. El apartado 99 expone las razones por las que la interpretación de la ley debe corresponder al tiempo en que se dictó. Del apartado 100 se pueden establecer sus ideas sobre la interpretación de la ley según la fórmula del texto y los elementos externos a esta. En el apartado 101 sigue su análisis en torno al verbo de la ley como instrumento que manifiesta la actividad consciente y reflexiva del legislador, sobre sus concepciones y el contenido de su voluntad. 


\section{II.4. La voluntad del legislador}

Dentro del apartado 102 se establece que toda investigación de la voluntad legislativa guarda relación lógica con el lenguaje en que se expresa, por lo que el intérprete acudiendo a leyes de distintos legisladores llega a una interpretación menos rigurosa. Inquiere, en el apartado 103, sobre los elementos externos al texto de la ley, los cuales pueden ser de índole diversa, para lo cual propone tres líneas de indagación de la voluntad del legislador: (i) en función de las relaciones que regula la ley (ratio legis), (ii) acorde al contexto en el que se dictó la ley (ocassio legis) y (iii) en los trabajos preliminares. En el apartado 104 desarrolla la función interpretativa de los trabajos preparativos de la ley.

\section{II.5. Sobre la interpretación extensiva y restrictiva}

En los apartados 105 al 108, encontramos las puntualizaciones sobre la interpretación extensiva y restrictiva, incluyendo los casos cuando el legislador provoca la insuficiencia o incertidumbre de la ley. Sobre la analogía, advierte que es distinta a la interpretación extensiva. La interpretación extensiva usa elementos extrínsecos de la ley para ampliar sus casos de aplicación, la analogía busca crear una decisión sobre la identidad entre las razones jurídicas del caso con la ley de aplicación. Solo menciona brevemente sobre las diferencias entre la analogía de la ley y la analogía del Derecho.

Finalmente observa que la analogía tiene a la ley escrita como punto de partida de la interpretación, que bien se puede acudir a otros métodos interpretativos e incluso otras fuentes siempre que se traten de "lugares visiblemente abandonados por las fuentes formales" (Gény, 1925, p. 304). También advierte que, al escoger el método interpretativo, se está predeterminando el contenido de la interpretación y por lo tanto de aplicación de la ley. Propone el axioma según el cual interpretar la ley depende de comprender la voluntad subjetiva de legislador.

\section{LAS NOCIONES DE LEY Y DE INTERPRETACIÓN}

Para Gény la interpretación se concreta en identificar el pensamiento del legislador contenido en el texto de la ley, sin dejar de distinguir la ratio legis entendida como la causa, fundamento o el principio de las relaciones objeto de la ley dictada. Reconocía las normas positivas del Código Napoleónico que incluían técnicas interpretativas como la analogía, que 
todavía constan en nuestros cuerpos legales ${ }^{1}$. Por ejemplo, el Código Civil ecuatoriano (2005), considera a la analogía en el artículo 18: "Los jueces no pueden suspender ni denegar la administración de justicia por oscuridad o falta de ley [...]. 7. A falta de ley, se aplicarán las que existan sobre casos análogos". Ello es en concordancia con el Código Civil español (1974), artículo 4.1: "Procederá la aplicación analógica de las normas cuando estas no contemplen un supuesto específico, pero regulen otro semejante entre los que se aprecie identidad de razón".

Aunque las normas escritas aportan a la judicatura un set de soluciones interpretativas, el autor no creía que fueran suficientes y se pudieran emplear para cualquier caso que se presente en la vida social. Según entendía, la aplicación de la norma jurídica positiva rechazaba a la costumbre, a la equidad y a los principios del Derecho, por lo que su trabajo se avoca en recuperar dichas fuentes como parte de su método de interpretación.

Cabe comentar que esta opinión de Gény (1925, pp. 25-26), ampliamente difundida por los partidarios del activismo judicial, históricamente olvida que el Código Napoleónico en varias de sus disposiciones remitía a la costumbre, a los principios del Derecho y a la equidad, así como también desconoce la monumental obra de los comentaristas franceses del siglo XIX que incluyeron en sus interpretaciones de la ley los principios del Derecho, la equidad o la jurisprudencia, como advierte Halpérin (2017).

Sobre la noción de la ley, desde un punto de vista formal, consideraba que esta es un producto de la sociedad que comprende un poder conformado democráticamente con competencia excluyente para formular disposiciones generales de interés común y "obligatorias para todos mediante sanción social" (Gény, 1925, p. 113), encontrándose la razón de su obligatoriedad tanto en su finalidad-proteger el tejido social—como en su condición racional.

La racionalidad de la ley presenta dos caras. Por una parte, depende que sea el resultado de la legislatura según los términos de la Constitución y expresada en el mismo lenguaje de quienes deberán observarla. La ley se distingue por el modo de producción que la legitima y le confiere su poder de obligar a todos los habitantes de un territorio dado, lo que depende de cómo esté organizado el legislativo y la "idea de la representación de aquellos a quienes la ley debe aplicarse" (Gény, 1925, p. 234).

\footnotetext{
${ }^{1}$ La obra de Napoleón tendría una influencia extraordinaria en el campo del Derecho. Por ejemplo, impactó en pensadores como Andrés Bello (1781-1865) quien redactó el proyecto de Código Civil de Chile, el cual influenciaría en la codificación de las normas civiles de varias repúblicas latinoamericanas, entre ellas el Código Civil ecuatoriano.
} 
Por otra parte, el contenido racional de la ley exige que se presente en forma de enunciados abstractos o generales, resultado de la isonomía jurídica que impone la estructura lógica de cada norma positiva como medio de aplicación de la ley en una sociedad siempre diversa y cambiante. Esto evidencia contradicciones en la relación de lo abstracto y lo concreto, como también una diferencia temporal desde que se dicta la ley hasta que se aplica. En consecuencia, una norma abstracta, en su aplicación a casos concretos, está condenada a presentar lagunas, así la ley "será siempre incompleta" (Gény, 1925, pp. 114-115) tal como lo justifica al citar a Aristóteles (2014), quien observó:

«La razón es que la ley es toda general, y en algunos casos no es posible hablar correctamente en general. Pues bien, en aquellos casos en que hay que hablar necesariamente, pero no es posible hacerlo correctamente, la ley abarca lo máximo posible, aunque no ignora que ello es erróneo. Mas no por eso es menos recta, pues el error no reside en la ley, ni en el legislador, sino en la naturaleza de las cosas: tal es la materia de la conducta. Por consiguiente, cuando la ley habla en términos generales, y ocurre en relación con ella algo contrario a la generalidad, entonces es correcto - allí donde el legislador resulta incompleto o yerra por hablar en generalrectificar lo que falta y lo que el propio legislador diría de esta manera, si estuviera presente, y habría legislado de saberlo. [...] Conque esta es la naturaleza de lo equitativo: una rectificación de la ley allí donde resulta defectuosa en razón de su generalidad» (p. 204).

Cabe matizar la afirmación de Gény sobre las lagunas del Derecho. Al respecto Kelsen (2013) señala cierta opinión sobre la existencia de las lagunas en el Derecho por causa de una conducta regulada negativamente, esto es, que en el plano normativo la conducta no forma parte de una condición a determinada consecuencia jurídica. Es una creencia errada en la medida que se sustenta en desconocer que cuando el orden jurídico no estatuye ninguna obligación a cargo de la conducta de un individuo, su conducta entonces está permitida (p. 255). Evidencia de esto lo encontramos en innumerables textos, por ejemplo, en la Declaración de los Derechos del Hombre y del Ciudadano (1789), en su artículo quinto: "La Ley tiene el derecho de prohibir solo acciones perjudiciales para la sociedad. Todo lo que no está prohibido por la ley no puede impedirse y nadie puede ser obligado a hacer lo que no ordena". Con lo cual, si entendemos al orden jurídico como un sistema, las lagunas del Derecho automáticamente se convierten en una imposibilidad lógica² ${ }^{2}$.

${ }^{2}$ Hay otros problemas que plantea la teoría de las lagunas del Derecho como la relación entre las normas y otros sistemas axiológicos como los valores morales, políticos, etc., o las lagunas técnicas que por yerro u omisión del legislador causan antinomias o 
Según Gény (1925) estas lagunas del Derecho cuando resultan de la insuficiencia de la letra de la ley o su ausencia, por causa de que los hechos de la realidad estaban fuera de la imaginación del legislador, no desdicen de que será la fórmula o texto de la ley la que "podrá dar la clave de soluciones nuevas, merced al empleo de los procedimientos que nos presta la lógica formal" (p. 31). Es claro que el autor no veía en las lagunas del Derecho un pretexto para desoír la ley. Por el contrario, consideraba que estas lagunas eran la oportunidad de extender los significados de la propia ley observando en ello su ratio legis y el conjunto del ordenamiento jurídico en los resultados de la interpretación.

Gény (1925) considera la interpretación de un texto legislativo semejante a la interpretación de un acto jurídico solemne, "cuyo contenido está encerrado en la fórmula auténtica que delinea claramente los contornos" (p. 258). Por ello interpretar es esclarecer la voluntad en el acto jurídico en cuestión, voluntad que se puede inferir de su contexto al tiempo en que se dictó la ley (ocassio legis) y su racionalidad, que se puede comprender en el marco constitucional de su producción, de su estructura lógica y principios (ratio legis).

No obstante, hay un factor adicional que explica su racionalidad, la cual se aprecia desde una perspectiva teleológica y que incidiría en la obligatoriedad misma de la ley, más allá de las percepciones individuales de bienestar o coacción. Lo que hace obligatoria a la ley es su racionalidad.

La racionalidad es un elemento basilar de su pensamiento y si bien distinguía como las principales cualidades de la ley otorgar "un máximum de seguridad y de certidumbre" (Gény, 1925, p. 232), pensaba que su fuerza obligatoria radica en su fundamento racional, cuando es coherente con sus fines declarados, que a su vez se pueden encontrar, según la escuela histórica, en los propósitos dictados por la conciencia popular expresada por el legislador. Según la tesis de Rousseau, su razón descansa al constituirse en expresión de la voluntad general. En cualquier caso, la racionalidad de la ley está marcada por su fin práctico, que busca alcanzar un cierto orden que la vida social exige.

Independientemente de la creencia de racionalidad que el intérprete estime como cierta en su fuero interno, la primera regla de la interpretación de Gény (1925) se concreta en una cuestión ética. Sin importar las convicciones personales de quien sea intérprete, la práctica y los resultados de su interpretación deben someterse a la "autocracia de la voluntad general" (p. 67). Así, la interpretación debe excluir a priori todo juicio personal que

indeterminación normativa, supuestos que por ahora no ahondaremos por ser ajenos a los fines del presente trabajo. 
perjudique el cumplimiento de la ley. Por ello cita a Fenet (1836) quien observa que "le premier effet de la loi est de terminer tous les raisonnemens, et de fixer toutes les incertitudes sur les points qu'elle réglé” (p. 67).

La interpretación del texto de la ley no es ocasión para reabrir el debate de las posibles soluciones sociales que pudo considerar el legislador. Para Gény la ley no es una fuente de Derecho a subestimarse. Siguiendo a Fenet (1836), la ley es el fin a todos los razonamientos previos a la solución que la sociedad reconoce legítima y que, manifestada en la forma prescrita por la Constitución, nos impele a cumplirla de modo irresistible y esto incluye a la práctica como a los efectos de la interpretación.

Gény (1925) considera que "las leyes naturales del espíritu humano exigen suponer en toda volición reflexiva la serie de deducciones racionales que permite el acto psicológico" (p. 275) que luego explican el contenido de la ley. No obstante, cualquier interpretación debe atenerse al texto en función de la voluntad del legislador. La interpretación como fenómeno intelectual, comprende en primer lugar encontrar en el texto de la ley el contenido entero de la voluntad del legislador. Por ello la interpretación debe seguir "el alcance que ha dado a la fórmula legal, y no debe dudarse en incluir en una disposición cuanto esta lleva consigo" (p. 274). En segundo lugar, está en identificar cuándo el intérprete hace las veces de "intermediario obligado entre la fórmula legal y la vida jurídica" (p. 246) ${ }^{3}$, lo que significa que tiene competencia y sus interpretaciones son soluciones jurídicas vinculantes.

Especial consideración merecieron las concepciones jurídicas del legislador plasmadas en la letra de la ley o sobreentendida en esta. Según Gény (1925) "las concepciones formuladas en su texto legal, deben siempre entenderse como relacionadas en todo lo posible a reglas positivas y desarrollarse con gran moderación en cuanto a las consecuencias que se deduzcan" (pp. 271-272). En otras palabras, su aplicación no debe traspasar el evidente alcance que ha querido al incluirlas en la ley el legislador y en tanto normas jurídicas, dichas concepciones son tan obligatorias como las demás.

En un ordenamiento jurídico pueden coexistir normas que responden no sólo a ideologías políticas diversas, modos de producción diferentes sino también a una organización social distinta. El autor nos recuerda la experiencia de la Convención Nacional en Francia de 1792, indicando que "las prerrogativas de la soberanía nacional no exigen más que una cosa, la libertad de modificar la legislación anterior" (Gény, 1925, p. 261). Esta

\footnotetext{
${ }^{3}$ La observación de intérprete e intermediario también se puede leer en Tarello (2018), cuando identifica en quien interpreta un mediador entre la fuerza del ius y las personas sometidas a sus disposiciones.
} 
observación la podemos constatar en la técnica de redacción constitucional en el presente, como se lee en la Constitución ecuatoriana de 2008: "Disposición derogatoria. Se deroga la Constitución Política de la República del Ecuador publicada en el Registro Oficial número uno del día once de agosto de 1998, y toda norma contraria a esta Constitución. El resto del ordenamiento jurídico permanecerá vigente en cuanto no sea contrario a la Constitución".

Por esta diversidad de contenidos que presentan las normas jurídicas, los cambios en la sociedad y la dinámica política siempre cambiante en el juego democrático, incide en que Gény (1925) se proponga averiguar "en qué momento debe colocarse el intérprete cuando pretende descubrir el pensamiento de la ley y las reglas que de ella se desprenden" (p. 260). En su respuesta solo hay dos posibilidades, o bien escogemos el tiempo de aplicación de la ley, o bien escogemos el tiempo en que se dictó la ley.

Si se prefiere interpretar la ley según la época de su aplicación, conllevaría a desconocer derechos adquiridos y se corre el riego de socapar, vía interpretación, el contenido de la ley a efectos de sustituir la voluntad de los interesados por extrañas consideraciones de un interés social superior al individuo o lo que en términos prosaicos actualmente entenderíamos refiere a las urgencias de la coyuntura política.

A efectos de interpretar adecuadamente la ley, nos atenemos a su fecha de expedición. Esto es, la interpretación "debe depender del momento de su origen, en todas sus partes" (Gény, 1925, p. 263), de tal modo que la judicatura solo debería considerar para fines interpretativos, al tiempo de su aplicación, los conceptos mudables y fugaces que tenga la ley como por ejemplo aquellos sometidos a un margen de apreciación tales como orden público. Al fijar el momento en que se dictó la ley, es factible estereotipar el carácter de ese momento con el propósito de lograr cierta permanencia en la interpretación que dependerá de alcanzar un "punto de observación estable" (Gény, 1925, p. 264).

\section{REGLAS BÁSICAS DE INTERPRETACIÓN}

Como una premonición del presente en que los métodos de interpretación se reproducen cuan amplio es el abanico político, un ejemplo de ello lo encontramos en la Ley Orgánica de Garantías Jurisdiccionales y Control Constitucional, que en el artículo 3.8, luego de una lista de métodos y reglas de interpretación, dispone: "Otros métodos de interpretación.- La interpretación de las normas jurídicas, cuando fuere necesario, se realizará atendiendo los principios generales del Derecho y la equidad, así como los 
principios de unidad, concordancia práctica, eficacia integradora, fuerza normativa y adaptación”. Gény (1925) advertía con absoluto acierto que escoger el modo de interpretación de la ley determina los resultados de su aplicación y que los modos usados en la interpretación tienen distintos grados de autoridad. Por ello pensaba que ante un juez las interpretaciones alcanzadas vía analogía "gozan de un poder menor y distan mucho imponerse con la misma energía” (p. 307).

El autor reconoce dos sets de criterios para la interpretación de los textos legales, un grupo basado en brocardos latinos que expresan las relaciones lógicas que deberán observar la aplicación de los enunciados normativos al momento de su interpretación y un segundo grupo de reglas que apelan a los elementos extrínsecos de la letra de la ley que pretendía recoger en su método de la libre investigación científica.

Es posible que estas reglas interpretativas respondan a los dos modos como reconocía a la ley, entendida como objeto de interpretación, según lo hacía un sector de la doctrina de su tiempo, concibiéndola como un producto social "absolutamente desprendida de la voluntad subjetiva del legislador" (Gény, 1925, p. 306); o reconociéndola como el resultado de un acto de voluntad reflexiva de la legislatura, razón por la cual solo llegamos a la comprensión cabal del texto de la ley considerando las razones de las voluntades que le dieron contenido.

La principal limitación de la ley es su contenido abstracto. Esta, frente a la dinámica de la realidad social, "jamás englobará todos los casos posibles" (Gény, 1925, p. 115) . Para este autor se trata de ocultar la insuficiencia de la ley cuando las nomas procedimentales exigen que las demandas, peticiones y recursos se funden en una ley o cuando se trata de controlar quién puede interpretar la ley con efectos vinculantes $\mathrm{u}$ obligatorios. Experiencias históricas como la interpretación legislativapermanente en el tiempo de Justiniano-resultaron insuficientes ${ }^{5}$.

Las lagunas técnicas, tales como las antinomias o inconsistencias en la norma positiva provocadas por el legislador, liberan al intérprete de encontrar en el texto de la ley el parámetro de validez del resultado de su interpretación. Para Gény (1925) no se puede pretender que se respete y aplique una ley cuyo texto no es claro o es inconsistente, en este caso "la interpretación recobra su libertad" ( $p$. 117). Conforme al principio legem potuit apertius dicere - que algunos autores lo refieren como contra eum qui legem dicere potuit apertius est interpretatio facienda-, en caso de duda toda interpretación debe ir en contra de quien debió haber hablado con

\footnotetext{
${ }^{4}$ No obstante, recuérdese que el legislador no está obligado a regularlo todo.

${ }^{5}$ Como, por ejemplo, el referimiento legislativo, cfr. Guzmán (1981).
} 
claridad $^{6}$. Este brocardo lo encontramos como norma positiva en el Código Civil ecuatoriano (2005), en el artículo 1.582:

«No pudiendo aplicarse ninguna de las reglas precedentes de interpretación, se interpretarán las cláusulas ambiguas a favor del deudor. Pero las cláusulas ambiguas que hayan sido extendidas o dictadas por una de las partes, sea acreedora o deudora, se interpretarán contra ella, siempre que la ambigüedad provenga de la falta de una explicación que haya debido darse por ella».

Pero esta máxima se plantea como una solución interpretativa que no busca el sentido de la voluntad de las partes, sino el sentido de sus actos en orden a los principios llevados a normas positivas. En consecuencia, el dato racional se encuentra en otro grado de la relación jurídica. Para ello debemos apelar al conjunto del régimen legal. No perdamos de vista los contenidos expresados en normas positivas, tal como ya lo indicará el propio Gény, es el texto de la ley o del ordenamiento jurídico donde encontraremos las claves de las soluciones, incluso en estos casos.

De esta manera la solución del legislador observa el principio de autonomía de la voluntad, resultando que por vía interpretativa no se agraven las restricciones a las que voluntariamente se hubiere sometido el deudor y, por otra parte, en los casos que el deudor hubiere propuesto la redacción dudosa, se entenderán sus términos en sentido favorable a la otra parte para evitar que el deudor se beneficie de su propia culpa o dolo. De este modo, el aforismo "no implica necesariamente una búsqueda del sentido auténtico del contrato, de la voluntad de las partes, sino más bien, una solución para problemas de cláusulas de imposible inteligencia o de muy dudoso valor" (Larrea y Merino, 2004, p. 271).

Siguiendo a Aristóteles, para Gény (1925) la equidad opera como fuente subsidiaria del Derecho positivo, en tanto la ley implica la supremacía de principios ideales y autónomos. Nuestro autor reconoce que estos principios superiores son extrínsecos a la ley, sin tener con su letra "ninguna relación directa y demostrable" (p. 40), y reconociendo que estos principios superiores no resultan de la voluntad del legislador o del pueblo, sino de esas relaciones necesarias emanadas de la naturaleza de las cosas como indica, citando a Montesquieu (2002):

\footnotetext{
${ }^{6}$ Así como la exégesis francesa recogió que los efectos nocivos de las cláusulas oscuras no deben recaer en quien no redactó el contrato, esta idea se traspasó al ámbito del Derecho Tributario bajo el principio in dubio pro contribuyente, según el cual las cláusulas oscuras o poco claras de la ley deberán ser interpretadas a favor del contribuyente y contra quien redactó las cláusulas, que es el legislativo, por ende, el Estado. Cfr. González (1997, p. 22).
} 
«Las leyes, en su significación más extendida, son las relaciones necesarias que derivan de la naturaleza de las cosas; y en este sentido, todos los seres tienen sus leyes [...]. Hay, por tanto, una razón originaria, y las leyes son las relaciones que se encuentran entre ella y los distintos seres, y las relaciones de estos seres distintos entre sí» (p. 87).

Gény (1925) pensaba que el proceso de interpretación debe alcanzar un punto de observación estable, a efectos de que refleje "con la mayor exactitud posible las relaciones de hecho que ha querido el legislador organizar jurídicamente, con todas las circunstancias que, determinándolas, ponen de relieve las exigencias morales, políticas, sociales, económicas y aún técnicas que el precepto debe dar satisfacción" (pp. 278-279), una vez organizadas las relaciones de hecho según sus principios y tomando en cuenta el fin de la ley buscado por el legislador, se podrá inferir la razón de la ley o ratio legis.

Para Gény (1925) alcanzar el punto de observación estable implica fijar los datos del medio social y jurídico en que la ley se promulgó, alinderados por los precedentes históricos, la influencia de legislaciones extranjeras y los trabajos preliminares de la ley (p. 279). En definitiva, el contexto ideológico por el cual nos aproximamos a los principios y conceptos no tanto por su valor intrínseco sino para indagar la medida en que "hayan podido ejercer influjo sobre el pensamiento subjetivo que ha elaborado la ley" (Gény, 1925, p. 282), de tal modo que podamos establecer el motivo preciso de la ley u ocassio legis según las ideas reinantes en la mente de sus autores.

\section{LOS CRITERIOS BROCÁRDICOS}

Gény no acude directamente a las normas de interpretación previstas en el Código Civil de Francia - al menos en el capítulo materia de este trabajo. En lo que entiende como el proceso de interpretación lógica del Derecho parece preferir los criterios brocárdicos, que a continuación indicaremos, como un medio en la reconstrucción del sentido entre la estructura lógica de la ley y su razón, para acceder a una interpretación congruente con la voluntad que la expidió, planteamiento que por las indefiniciones a las que recurre ha merecido críticas, como podemos observar: 
«Gény-autor proclive a la vaguedad terminológica y a la confusión conceptual-denominara "interpretación lógica", a saber, la búsqueda, más allá de las palabras de la ley, de un misterioso "pensamiento de la ley" localizado en el espíritu de su autor, el legislador. Esto, claro está, nada tiene que ver con lógica alguna» (Vernengo, 1994, p. 115).

\section{V.1. Cessante ratione legis, cessat lex ipsa}

De este axioma se infiere que, si cesa la razón de la ley, entonces cesa la ley misma. Esta máxima no deja de ser controvertida, por más que parezca razonable prima facie. Por ejemplo, encontramos su aplicación en la ley marcial o en el estado de excepción, en la Constitución de la República del Ecuador (2008), artículo 166: "Cuando las causas que motivaron el estado de excepción desaparezcan, la Presidenta o Presidente de la República decretará su terminación y lo notificará inmediatamente con el informe correspondiente". Según la máxima, no se requiere derogar expresamente la norma, esta se abroga a sí misma cuando cesan las causas que la originaron. No obstante, lo controvertido de su aplicación aparece cuando se trata de establecer cuál es la razón o causa de la ley, y resultará discutible puesto que invariablemente el juez recurre a elementos extrínsecos a esta para aplicarla ${ }^{7}$.

\section{V.2. Inclusione unius fix exclusio alterius}

Algunos autores también se refieren al brocardo como expressio unius est exclusio alterius. Por este aforismo cuando una ley, estatuto, contrato u otro documento legal incluye una lista de elementos que pertenecen a una categoría, se debe suponer que cualquier elemento fuera de la definición está excluido intencionalmente. Así en los conflictos entre una ley anterior y una ley posterior, la legislación posterior sobre un tema cubierto por una ley previa conlleva que las reglas de la ley anterior no son reemplazadas por las de la ley posterior, salvo que así aparezca expresamente en esta última.

Este aforismo aparece, por ejemplo, en la sentencia United States v. Barnes, 222 U.S. 513 (1912), en la que la Corte Suprema de los Estados Unidos manifestó: "The maxim expressio unius est exclusio alterius is a rule of construction, and not of substantive law, and serves only as an aid in discovering legislative intent when not otherwise manifest". De igual modo

\footnotetext{
7 En los sistemas de Derecho consuetudinario esto cobra relevancia al momento de identificar el stare decisis por parte de los jueces al aplicar un precedente, dado que el juez puede recurrir a un marco axiológico distinto al usado al establecer las circunstancias que motivaron el precedente.
} 
se encuentra en el Código Civil ecuatoriano, en su artículo 39: "la ley especial anterior no se deroga por la general posterior, si no se expresa”.

Aforismos como este ya estaban acotados en la legislación en el tiempo de Gény. En un caso actual, el Código Civil ecuatoriano (2005) dispone en su artículo 1.581: "cuando en un contrato se ha expresado un caso para explicar la obligación, no se entenderá por solo eso haberse querido restringir la convención a ese caso, excluyendo los otros a que naturalmente se extienda". Presenta un claro ejemplo de cómo el legislador ha limitado el alcance del aforismo inclusio unius est exclusio alterius. Como resultado, sea en la ley o en un contrato, el caso planteado en un documento legal busca prevenir que las partes entorpezcan el cumplimiento de sus obligaciones, por lo que no debería interpretarse con efectos restrictivos sobre la voluntad de los contratantes o los términos de la ley, salvo "cuando aparezca realmente que la voluntad de las partes fue la de excluir otros casos diversos del significado en el ejemplo propuesto" (Larrea y Merino, 2004, p. 270).

\section{V.3. Argumentum e contrario}

Este argumento supone evitar extender lo predicado en un enunciado normativo a elementos o sujetos que no estén incluidos estrictamente en este. Jurídicamente su aplicación se enmarca en el aforismo ubicumque lex voluit dixit, ubi tacuit noluit - si el legislador hubiera querido decir algo, lo habría dicho expresamente. Nótese que la aplicación estricta del aforismo opera en dos niveles, puede ser literal respecto al texto de la ley o lógica en orden a la razón de la norma. Si no se cuidan estos niveles puede llevar a una aplicación ciega de la letra ley por sobre la intención del legislador ${ }^{8}$.

En la interpretación así obtenida, Gény advierte dos reservas a los resultados de su aplicación. Primero, no puede contradecir principios generales del Derecho, y segundo, no puede resultar restrictiva al ejercicio de derechos. De hecho, la interpretación restrictiva de la ley "no es legítima ante un texto normativo deliberadamente general, aun cuando el legislador no hubiere previsto todas las consecuencias económicas de su decisión" (Gény, 1925, p. 291).

\footnotetext{
${ }^{8}$ Un ejemplo reciente fue el surgimiento del comercio electrónico y hasta la promulgación de la ley que lo reguló, medió un tiempo en que se discutía si el mensaje de datos podía tener igual valor jurídico que los documentos escritos. Ciertamente el legislador de aquel entonces no podía haber incluido al mensaje de datos y valorar su eficacia jurídica en determinadas transaccionales mercantiles, pues no existía la tecnología, pero hubiera resultado un absurdo y un desastre económico desconocer que, a pesar de no haber estado comprendido en la letra de la ley, el mensaje de datos cumplía y cumple la razón de las normas respecto a la manifestación de la voluntad y su prueba. Sobre la prueba electrónica, cfr. Riofrío Martínez-Villalba (2004).
} 


\section{V.4. Argumento "a pari" o "a simili"}

Se fundamenta en razones de semejanza y de igualdad entre el hecho o enunciado normativo propuesto y el resultado de la inferencia o conclusión. La interpretación no recae en el texto de la norma, sino en evidenciar que el resultado de la interpretación es correcto al observar semejanzas entre el enunciado de la ley y el caso. Cualquier argumento $a$ pari requiere identificar la norma vigente aplicable al caso ${ }^{9}$. Para Gény (1925) el argumento a pari es la "analogía propiamente dicha" (p. 32), afirmación que se entiende referida a la acepción vulgar del término reducido a una relación de semejanza entre cosas o relaciones diferentes.

\section{V.5. A majori ad minus}

También llamado por algunos autores com a maiore ad minus, es un argumento por el cual quien interpreta extiende los términos del enunciado normativo a un objeto que no está expresado en este. La operación lógica es convincente solo si al extender los términos del enunciado normativo se preserva la misma razón prevista en la ley. En el campo legal aplica a normas jurídicas permisivas. Este argumento se suele expresar como "quien puede lo más, puede lo menos". Por ejemplo, si la ley o un título jurídico otorga la propiedad sobre un bien inmueble, con mayor razón permitirá al dueño el derecho a disponer del bien, por ejemplo, hipotecándolo, aunque la ley o el título no lo hubiere considerado expresamente.

En el campo del Derecho administrativo ecuatoriano, podemos observar expresado este brocardo en la presunción de competencia y facultades implícitas prevista en el Estatuto del Régimen Jurídico Administrativo de la Función Ejecutiva, en el derogado artículo 86:

«Si alguna norma atribuye competencia a la Administración Pública Central, sin especificar el órgano que deba ejercerla, se entenderá que la facultad de tramitar y resolver las peticiones o impugnaciones corresponde a los órganos inferiores competentes por razón de la materia y del territorio y, de existir varios de éstos, al superior jerárquico común. Los órganos administrativos serán competentes para resolver todos los asuntos y adoptar todas las medidas y decisiones que los consideren razonablemente necesarios para cumplir con sus objetivos específicos

\footnotetext{
${ }^{9}$ El uso de los argumentos a pari son comunes en la praxis del Derecho, razón por la cual, en las sentencias y resoluciones administrativas, se incluye un contenido específico sobre la competencia de la autoridad que decide y la pertinencia de la norma respecto al caso en orden a los elementos fácticos y jurídicos constantes en el expediente, lo que llevado al terreno de las normas positivas se comprende en el deber constitucional de motivación.
} 
determinados en la ley no obstante que dichos asuntos, medidas y decisiones no hayan sido expresas y detalladamente a ellos atribuidos».

\section{V.6. A minori ad majus}

Este, que para algunos autores es argumentum a minore ad maius, es un argumento por el cual el intérprete asume como premisa menor la prohibición de un enunciado normativo y lo extiende a otro caso no previsto expresamente en este, siempre que la inferencia al caso cumpla las condiciones exigidas por la razón impeditiva del enunciado normativo. En el ámbito jurídico esta argumentación aplica a disposiciones restrictivas o prohibitivas, y se suele expresar como "si está prohibido lo menos, está prohibido lo más". Por ejemplo, si un enunciado normativo dispone no pisar el césped (premisa menor), el intérprete debe identificar la razón de la prohibición - al caso, no dañar el césped - entonces concluye que conductas como cavar o conducir un vehículo sobre césped, aunque no supongan pisarlo, también están comprendidas en la prohibición del enunciado normativo (premisa mayor).

\section{V.7. Ubi eadem ratio, idem jus}

En algunas referencias se encuentra como ubi est eadem ratio, ibi idem ius. Por este latinazgo se asume que la ley es racional y lo es porque responde a una razón. Entonces, cuando hay la misma razón en ciertas circunstancias, la ley es la misma para esas circunstancias y en consecuencia se debe emitir el mismo juicio. Es lo que se conoce como la interpretación extensiva de la ley, cuando a un caso se aplican las consecuencias jurídicas dispuestas por una ley que originalmente no lo previó, en tanto guarde identidad sustancial con la razón de la ley o ratio legis.

No obstante, para aplicar está máxima, el enunciado normativo materia de la interpretación no debe revestir el carácter excepcionalexceptio et strictissima interpretationis. Si se aplica distraídamente el aforismo ubi est eadem ratio, ibi idem ius dará como resultado la creación de restricciones al ejercicio de derechos no previstas en la ley.

Sobre la analogía ${ }^{10}$, como habíamos indicado, Gény (1925) advierte que es distinta a la interpretación extensiva. En esta última el intérprete puede recurrir a elementos extrínsecos de la ley para ampliar los casos de aplicación, en tanto la analogía busca crear una decisión sobre la identidad entre las razones jurídicas del caso con su ley de aplicación. La

\footnotetext{
${ }^{10}$ Razonamientos que en la mayoría de los ordenamientos jurídicos iberoamericanos está expresamente prohibido en el ámbito penal, tributario y administrativo sancionador.
} 
interpretación por analogía no se detiene a buscar la intención del legislador, lo que trata el intérprete realmente es crear una voluntad puramente hipotética del legislador, "fundada sobre la idéntica razón jurídica ( $u b i$ eadem ratio, idem jus)" (p. 297). En consecuencia, la analogía tiene como propósito subvenir el texto oficial de sus deficiencias. En cualquier caso, la interpretación, incluso por analogía, debe apoyarse en las disposiciones del Derecho escrito como un referente de la validez de sus resultados.

La analogía puede enfrentar circunstancias en que la razón de la ley o ratio legis merezca varias interpretaciones. Esto se puede superar regresando sobre los elementos del caso y estableciendo la ratio iuris o fundamento jurídico de la ley o del acto o contrato que se trate. La ratio iuris se encuentra en el Derecho vigente, por lo cual saldrá a la luz verificando la conexidad entre el instituto y los artículos relacionados que consten en la ley como en otros cuerpos legales.

Gény (1925) consideró que "se ve marcadamente el carácter mix to de la analogía" (p. 303), dado que puede aplicarse tanto en la interpretación de la ratio legis como de la ratio iuris. No obstante, advertía que sin el debido control jurisdiccional o constitucional y sin atenerse a principios del Derecho como la equidad o el interés general, fácilmente se puede prestar para encubrir el manto legal del legislador con criterios subjetivos del intérprete, por ello la insistencia en "volver a buscar el contenido de la fórmula legislativa, auxiliado por la fórmula que lo expresa" (p. 257). Aun cuando se alegue en contra del texto de la ley su imperfección o su inadecuada adaptación al medio social, el intérprete "no puede ni debe servirse de ellos más que para aclarar el diagnóstico de la voluntad del legislador, no para disponer o rectificar dicha voluntad" (ibíd.).

\section{EL MÉTODO DE LA LIBRE INVESTIGACIÓN CIENTÍFICA}

Según Gény, el método de la libre investigación científica tiene su punto de encuentro con el método savigniano que frente a las lagunas acude a la analogía, pero se opone al método exegético ya que este carece de un método científico y no se ocupa de analizar las necesidades de la sociedad. Como representante de la escuela francesa de Derecho social, su método se caracteriza por una interpretación jurídica que acude a otras fuentes de Derecho y a otras ciencias o disciplinas para arribar a sus conclusiones, pero en el marco de su eclecticismo metodológico reconocía que la finalidad de la interpretación es descubrir el pensamiento del legislador para que se revelen las circunstancias dominantes de la época en la que se formuló y no sólo considerar las circunstancias del tiempo de aplicación de la ley, aunque 
reconozca que "el Derecho debe satisfacer las necesidades de la vida jurídica actual" (Gény, 1925, p. 259).

Gény (1925) consideró dos tendencias en la interpretación de la ley. Una la interpretación lógica en la que se incluye la gramatical y otra en que la ley aparece como "una entidad independiente, evolucionando con el medio social, y explicable según las transformaciones de este medio" (p. 284). Esta última tendencia nos orilla a considerar los medios extrínsecos a la letra de la ley, los cuales deben propender a descubrir la voluntad del legislador, bien porque falte, bien porque sea deficiente para imponerse, casos en los que la solución habrá de buscarse en otra fuente formal del Derecho u obtenerla con la libre investigación científica.

Otra creencia de Gény (1925) era considerar pueril oponer "la interpretación gramatical a la interpretación lógica" (p. 267). Según él se complementan, ambas se requieren para entender el desenvolvimiento de la voluntad del legislador. No obstante, señala que la dicotomía entre letra y espíritu no es inocente y que "el descubrimiento de la intención ha de predominar necesariamente, pero la letra interviene como manifestación auténtica y solmene del espíritu, inseparable de este, y cuyo objeto es ponerlo de manifiesto" (pp. 267-268).

Lo anterior es una clara influencia de la tradición romana en Gény, considerando que en la Ley de las XII Tablas (450 y 451 a.C.), se dispone: cum nexum faciet mancipiumque, uti lingua nuncupassit, ita ius esto (Tabla VI). En virtud de esta, cuando alguien hace un nexum o una mancipatio, como lo pronuncia solemnemente, será su ley, evidencia de una tradición jurídica respecto al uso de las palabras que se mantiene hasta nuestros días, por la cual el alcance de la ley y del contrato dependerá del contenido y medida de las palabras utilizadas en estos instrumentos.

En efecto, para Gény (1925) las condiciones sociales actuales solo merecen aplicarse como elementos interpretativos "en la medida en que ayudan a descubrir la voluntad soberana que constituye exclusivamente su esencia" (p. 292). Si bien reconocía el valor que pueden aportar en la interpretación los trabajos preliminares o preparatorios de la ley manifestados en documentos oficiales, no dejaba de reconocer que son difíciles de interpretar y los acogía como "ilustraciones autorizadas del texto" (p. 286) a condición de que no contradigan la ley.

Gény veía más fructífera la distinción que puede hacerse entre el texto y los elementos ajenos a este en el proceso intelectual de la interpretación. Dicha ajenidad corresponde a los elementos que ayudarían a explicar la voluntad del legislador que los encontramos, entre otros, en los ideales, valores o principios, así como en fenómenos de orden psicológico y social. Pero también alerta que recurrir a estos bien puede provocar una 
transformación del sentido de la ley querido por el legislador, cuando la interpretación debe buscar acaso la reafirmación o suplir del texto oficial y no su negación, debiendo para ello el intérprete considerar como límites, los impuestos por las palabras y los fines declarados de la ley.

El contenido del texto legal, como proposición lógica subordinada al cumplimiento de ciertos hechos, para que produzca una consecuencia, constituye a la ley en la premisa mayor de un silogismo que la judicatura completará con el caso que se le someta a su conocimiento y competencia. Pero es un silogismo que hace sentido en tanto quien administre justicia crea en dos supuestos: el primero la omnipotencia legislativa, según la cual las normas positivas son suficientes para ofrecer soluciones que resuelven todos los hechos de la vida en sociedad. El segundo es la racionalidad de la ley, por la cual esta no es un producto inmediato del entorno social. Aceptarlo implica confundirla con el Derecho consuetudinario, cuando lo que distingue la ley es la actividad reflexiva del legislador.

No obstante, sin dejar de reconocer la tensión entre la discreción judicial y el texto de la ley, Gény (1925) advertía que sería irracional propugnar en sede judicial un sistema de interpretación que usa el texto de la ley para justificar otra cosa, distinta a lo que en ella se quiso estatuir. La ley es un producto social, eso no lo negaba, pero además de ser un producto de la sociedad que la crea y a la cual regirá, reconocía que el legislador juega un papel activo en el proceso de construcción de su racionalidad de modo que interpretar la ley prescindiendo de su pensamiento y su voluntad, conllevaría a suprimir "la precisión y la estabilidad, que constituyen el mérito principal, al mismo tiempo que la ventaja más notable de la ley escrita" (p. 255).

Interpretar la ley sin considerar la voluntad subjetiva del legislador convierte a la ley en "una especie de saco vacío, que cada cual puede llenar a su antojo" (ibíd.). Esta era una tendencia que el propio Gény (1925) combatirá, pues sostenía que al sacrificar la voluntad del legislador que dictó la ley en cualquier proceso intelectual de interpretación desconocería en la ley "su esencia y razón de ser" (ibíd.):

«Esta es la mayor laguna de la escuela histórica, el descuidar, bajo el influjo sectario y de una especie de determinismo exclusivo, la parte incontestable que toma la actividad consciente y reflexiva del hombre, en la formación del derecho. Esta actividad prepondera exclusivamente en la ley escrita; ésta no es otra cosa, en su esencia, que la expresión de la voluntad inteligente; y es opuesto a su naturaleza el interpretarla de otro modo que como un acto de voluntad» (pp. 255-256). 


\section{ConclusioneS}

De la investigación puede concluirse lo siguiente:

1. Se puede destacar el esfuerzo de Gény por describir el fenómeno de la interpretación partiendo de su causa primera, la contradicción al aplicar una ley escrita en términos abstractos y una realidad tan diversa como cambiante. Para resolver esta contracción, parte de que la ley resulta insuficiente. Con ello justifica recurrir a otras fuentes del Derecho como por ejemplo la equidad, para corregir lo que la generalidad de la ley o la imaginación del legislador no alcanza a regular o regulando la realidad, lo hace en defecto de principios superiores en orden a la naturaleza de las cosas.

2. Gény procura identificar el dato racional en la praxis y en el producto de la interpretación, que lo encuentra en la racionalidad de la ley, desde su producción mediante un órgano representativo de toda la sociedad en la que el legislador participa reflexivamente, su estructura lógica y abstracta, los fines que persigue, los paradigmas al tiempo en que esta se dictó, sus circunstancias (ocassio legis) y en orden tanto de la ratio legis como de la ratio iuris.

3. Sobre la imagen que pretende mostrar un Gény subestimando a la ley o reaccionando contra las fórmulas lógicas que exige su interpretación, su texto muestra algo completamente diferente, de hecho, reconoce el valor de la lógica para su debida interpretación. También aclara que el apelar a sus elementos extrínsecos cabe solo a condición de que realmente exista el silencio o una insuficiencia evidentísima de la ley. Por último, reconoce que el valor intrínseco de la ley radica en su legitimidad social conforme su proceso democrático de formación.

4. En la relación entre la ley escrita y la interpretación, Gény fija el texto de la ley o del conjunto de leyes, como el principal elemento para validar el producto de toda interpretación jurídica, cualesquiera que sean sus causas o los criterios interpretativos empleados. Sin que sea legítimo para quien interprete subvertir el contenido de la ley en orden a privilegiar sus creencias personales y sometiendo los resultados de su interpretación a la autocracia de la voluntad general. 


\section{REFERENCIAS}

Aristóteles (2014). Ética nicomaquea (J. L. Calvo Martínez, trad.). Alianza Editorial.

Ecuador (2002). Decreto Ejecutivo 2428 de la Presidencia de la República. Estatuto del

Régimen Jurídico Administrativo de la Función Ejecutiva. Registro Oficial No. 536, de 18 de marzo de 2002.

Ecuador (2005). Ley 2005-010. Codificación del Código Civil. Registro Oficial No. 46, de 24 de junio de 2005 .

Ecuador (2008). Constitución de la República. Registro Oficial No. 449, de 20 de octubre de 2008.

Ecuador (2009). Ley Orgánica de Garantías Jurisdiccionales y Control Constitucional. Registro Oficial No. 52, de 22 de octubre de 2009.

España (1974). Decreto 1836/1974. Texto articulado de la Ley 3/1973, de 17 de marzo, de Bases para la Modificación del Título Preliminar del Código Civil. Boletín Oficial del Estado No. 163, de 9 de julio de 1974.

Estados Unidos (1912). Sentencia 222 U.S. 513 de la Corte Suprema de Justicia.

Fenet, P. A. (1836). Recueil complet des travaux préparatoires du Code Civil. Videcoq.

Gény, F. (1925). Método de interpretación y fuentes en derecho privado positivo (R. Saleilles, trad.). Reus.

González, E. (1997). La interpretación de las normas tributarias. Arazandi.

Guzmán, A. (1981). Historia del "referimiento legislativo". Revista de Estudios HistóricoJurídicos, 6, 13-76.

Halpérin, J. L. (2017). Exégesis (escuela) (A. Botero Bernal, trad.). Revista de Derecho de la Universidad del Norte, 48, 263-277.

Justiniano (1889). Cuerpo del Derecho Civil Romano (I. L. García del Corral, trad.). Jaime Molinas Editor.

Kelsen, H. (2013). Teoría Pura del Derecho (R. J. Vernengo, trad.). Porrúa.

Larrea, J., y Merino, R. (2004). Derecho Civil del Ecuador (XI). Corporación de Estudios y Publicaciones.

Montesquieu, C. S. (2002). El espíritu de las leyes (D. Castro Alfín, trad.). Istmo.

Riofrío Martínez-Villalba, J. C. (2004). La prueba electrónica. Temis.

Tarello, G. (2018). La interpretación de la ley. Palestra.

Vernengo, R. (1994). La interpretación literal de la Ley. Abelardo-Perrot. 